\title{
Memórias dançantes: a (re)invenção de uma tradição por grupos de coco de mulheres no Cariri - CE
}

\author{
Memories dancing: the reinvention of tradition by women coco \\ groups in Cariri - CE \\ Camila Mota Farias ${ }^{1}$ \\ camilamotafarias@gmail.com
}

\section{Resumo}

Este artigo possui o objetivo de analisar como grupos de mulheres no Cariri cearense se apropriam da dança do Coco, construindo uma tradição. Utilizando as metodologias da História Oral e do trabalho de campo, realizamos nove entrevistas, com mestras e dançadeiras, que são as fontes dessa reflexão com letras de músicas de suas autorias. Por meio das memórias das mulheres, percebemos que, ao se apropriarem da dança do Coco, ressignificam a manifestação, (re)inventando uma tradição, processo que incide sobre suas identidades e produz um Coco de diferença, constituído pelo passado/presente. Assim, o artigo está dividido em três momentos: inicialmente, uma discussão sobre Dança, História Oral e Memória; em seguida, uma apresentação da dança do Coco e dos grupos estudados; e, por fim, são tecidas reflexões sobre algumas movimentações possíveis de memórias dançantes.

Palavras-chave: dança; memória; tradição; história oral.

\begin{abstract}
This article has the objective to analyze how women's groups in Cariri cearense do appropriation of Coco's dance, creating a tradition. Using the methodologies of oral history and fieldwork, we conducted nine interviews with mestras and dançadeiras, which will be the source of this reflection, along with songs of his authorship. Through the memories of women, we realized that by incorporating Coco dance, women redefine the manifestation, (re)inventing a tradition, process that interferes on their identities and produces a Coco of difference, made by past / present. Thus, the article is divided into three stages: first a discussion of Dance, Oral History and Memory, then a presentation of Coco dance and groups, and, finally, reflects on some possible movements of memories dancing.
\end{abstract}

Keywords: dance; memory; tradition; oral history.

1 Mestranda em História pelo Mestrado Acadêmico em História e Culturas (Universidade Estadual do Ceará - UECE), com bolsa Capes. Integrante do Laboratório de Estudos e Pesquisas em História e Culturas (DÍCTIS). Graduada em História pela UECE. 


\section{I - Dança, História Oral e Memória}

A produção nacional sobre Dança vem crescendo desde a década de 1980, entretanto, "ao se falar de arte, grande parte das reflexões se concentram sobre a música, teatro e pintura, isto é, a dança não dispõe de escritas de peso que auxiliem na compreensão dos processos sociais que forjaram e ainda forjam sua prática em sociedade" (GUARATO, 2010: 24). Sendo assim, é um campo de estudo ainda recente.

O conhecimento produzido nessa área tem se centrado, principalmente, em questões sobre o corpo, como sugere Arraias (2013: 70) "O ambiente da universidade pode possibilitar a artistas e não artistas "desvendar” as miríades teóricas do saber prático e as miríades práticas do saber teórico de dança, priorizando, nesse desvendar, o entendimento do corpo e seu funcionamento no mundo". Assim, essa produção pensa o corpo, técnicas de movimento, estética, performances do corpo em cena, processos de criação e demais relações possíveis.

Nos diálogos estabelecidos entre a Dança, temos a interface com a História, que, a partir de uma abordagem interdisciplinar, pode pensar as danças populares que possuem, ainda, uma lacuna nesse campo do conhecimento, pois a maioria dos estudos sobre o tema não partem de abordagem historiográfica, não compreendem as danças como promotoras de saberes, de relações sociais, de experiências e de histórias, ou seja, não problematizam as transformações/permanências, assim como as relações tecidas nas danças e a partir das danças nas sociedades, percebendo que há nesse processo uma relação simbiótica.

Assim, em busca dos movimentos de sujeitos em tempos e espaços demarcados, propomos compreender a trajetória social de uma prática cultural popular em suas construções e reinvenções e, nessa proposta reflexiva, entendemos que as manifestações populares revelam aspectos das vidas dos sujeitos que a praticam, ao mesmo tempo em que se constituem por esses sujeitos.

Ao se propor uma dança popular como objeto de estudo, é preciso compreender a totalidade dessa manifestação, assim como suas articulações com as culturas populares e outras práticas. Tendo em vista que são constituídas de várias linguagens, então, "a dança popular não pode ser apreciada separada da música, do poema, da linguagem cênica, do conjunto dos espetaculares da festa, na qual se insere" (MONTEIRO, 2011: 44-45). É preciso compreender, também, os seus contextos de criação e de fruição, pois que existem várias maneiras de experimentar as danças, inclusive ao pesquisar, e as danças também se dizem em várias linguagens.

Portanto, as danças, assim como as brincadeiras e as músicas populares, fazem parte da vida social, produzem significados e conhecimentos. "[...] Cuando miramos las danzas, ritos y otros fenómenos de este tipo, estamos observando sistemas humanos estructurados de significados que son objetos de comunicación y que son, entre otras cosas, objeto de conocimiento" (WILLIAMS, 2010 in CAROZZI, 2011: 17). Assim, os estudos sobre danças e culturas revelam dimensões da vida humana que muitas vezes não são perceptíveis em outras abordagens.

Entendendo que os produtores das danças populares, em sua maioria, não dominam a escrita e seus saberes são repassados por meio da oralidade, e que a dança é uma arte efêmera que "se faz" no momento de sua realização e após esse momento deixa de "existir", sendo assim, seus registros ocorrem no momento em que flui (filmagem, fotografia, entre outras), porém, como entende Christine Greiner (2012: 40), o que "insiste em permanecer em meio à fugacidade da natureza da dança é a sua ação sígnica, o seu pensamento", assim, na falta de registros ou em busca dos signos, dos significados e das maneiras de apropriação, produção e experimentação da prática cultural, ou seja, da reconstrução de processos históricos, propomos como suporte memórias que estão em movimento e representam uma dança popular.

As memórias podem ser reveladas por meio da História Oral, espaço de contato interdisciplinar que permite, com métodos e técnicas, interpretações qualitativas de processos históricos e sociais, centrada na subjetividade das experiências humanas, visões e versões dos atores sociais. Para Portelli (1997: 15), a História Oral:

[...] Embora diga respeito - assim como a sociologia e a antropologia - a padrões culturais, estruturas sociais e processos históricos, visa aprofundá-los em essência, por meio de conversas com pessoas sobre a experiência e a memória individuais e ainda por meio do impacto que elas tiveram na vida de cada uma. 
Por meio dessa metodologia, com a realização de entrevistas, produz-se uma fonte. As fontes orais, portanto, são fontes construídas, resultado de um trabalho entre pesquisador e depoente. O narrador não é mais o que viveu o acontecimento, pois sofre interferência de seu presente e de suas vivências, portanto, podemos afirmar que se constituem como fontes relacionais, baseiam-se na comunicação e na troca marcadas por diálogos entre passado e presente, público e privado, oralidade e escrita, pesquisador e depoente (PORTELLI, 2013).

Essa proposta metodológica materializa-se concomitantemente a realização do trabalho de campo, metodologia desenvolvida a partir de observações participantes e de descrições etnográficas, que não se resumem a narrar o visto, mas a, além de descrever densamente, interpretar os fatos observados. A etnografia permite a produção de uma leitura sobre como os sujeitos significam o mundo e a si, produzem suas existências e relações (GEERTZ, 1989). Por meio desse contato com o outro, pode ser construído um diário de campo e produzido entrevistas que se constituem em narrativas produtoras de sentidos, associadas a práticas sociais também geradoras de sentido, assim, o sentido se produz coletivamente a partir das interações sociais e dos contextos experimentados pelos sujeitos que criam conceitos/noções para compreender e vivenciar os fenômenos a sua volta.

Muitos estudos que trazem como objeto práticas e produções artísticas recorrem à metodologia da História Oral, porém a produção sobre História Oral no Brasil possui uma nascente discussão sobre esse uso e suas possibilidades, como sugere Ricardo Santhiago (2013), em estudos que envolvem a busca pelos processos de criação e por ideias e conceitos artísticos, acrescentaríamos, ainda, pelas poéticas populares e seus fluxos.

A oralidade, então, revela aspectos nem sempre percebidos em outras fontes, espaços sociais marginalizados, por meio de memórias (JUCÁ, 2003). Compreendemos que a memória possui sua historicidade, não é natural, imutável do aparelho cognitivo. O ato de recordar refere-se ao íntimo do sujeito, essas recordações constituem, assim, uma memória pessoal, mas esse processo [a rememoração] se dá em contato com o outro, então a memória também é social. Portanto, a memória é subjetiva, construída por linguagem, ensino, observações, ideias coletivas e experiências partilhadas (FENTRESS; WICKHAM, 1992). Quando trabalhamos a memória como fonte, não podemos ignorar a subjetividade e seu caráter social, ou sobrepor esse caráter ao aspecto pessoal da memória.

Quando recordamos, elaboramos representações de si, dos outros, do mundo, e nos constituímos a partir do que lembramos, e do que esquecemos. Recordamos conhecimento e sensações em um processo no qual a memória penetra em todos os aspectos da nossa vida mental, dos conscientes aos inconscientes. Estas memórias são construídas a partir das linguagens, dos lugares, das experiências partilhadas, selecionando o que deve, ou não, ser lembrado e gerando elementos de identificações, ou seja, a partir de um esforço e de um trabalho de rememoração que envolve as conjunturas socioculturais de produção. Nas Palavras de Ecléa Bosi (1994: 55): "na maior parte das vezes lembrar não é reviver, mas refazer, reconstruir, repensar, com imagens e idéias de hoje, as experiências do passado", permitindo, portanto, uma compreensão desse tempo presente.

A abordagem sobre as danças populares pode ir além da busca pelas memórias pela recorrência à História Oral. Podem ser pensadas e problematizadas a partir do cantar, o que cantam e como cantam, em busca de compreender como essas poéticas se relacionam com as vidas e as concepções de mundo dos sujeitos que as produzem (NAPOLITANO, 2005). No dançar/cantar identificamos um processo de comunhão em que a prática é produzida por evocações de memórias e, ao mesmo tempo, o dançar/cantar produz memórias, ou pensamentos que emergem da própria prática (VILELA, 2010; ROCHA, 2012). Essas memórias dançantes não dizem apenas sobre a prática cultural, mas sobre seus produtores, suas experiências e seus sentimentos pessoais e compartilhados, estão também em movimentos e fluxos, assim como o dançar.

\section{II - Sobre o dançar/cantar Coco no Cariri}

Entendemos o Coco como uma prática das culturas populares brasileiras; pode ser encontrado no litoral e no sertão nordestino. Acredita-se que a introdução dessa prática no Nordeste brasileiro se deu através dos escravos 


\section{Artigos}

africanos que catavam e quebravam coco em um ritmo de trabalho no qual emergiu a música (CASCUDO, 2012; ANDRADE, 2002). Os Cocos podem ser classificados em três gêneros: dançado, em embolada e em literatura de cordel (ARAUJO, 2013). Dentro destes, existem várias modalidades que dependem da métrica, dos instrumentos, do local e da coreografia ${ }^{2}$. Nos Cocos dançados, identificamos a presença de elementos indígenas, os movimentos em roda e a estrutura poético-musical, e de elementos das culturas negras, os instrumentos de percussão utilizados ${ }^{3}$, a umbigada ${ }^{4}$, o ritmo e o canto com estrofes normalmente improvisadas e refrão fixo. Assim, afirma-se sua origem afro-indígena (AYALA; AYALA, 2000).

No Ceará, essa dança pode ser encontrada em diversas regiões ${ }^{5}$, principalmente nas áreas litorâneas, com exceção do Cariri, situado no sertão cearense. Em cada localidade, sua vivência e produção ocorrem de formas específicas, seja nos passos, nos instrumentos, nas experiências decorrentes do dançar/cantar Coco e na significação da prática cultural. Portanto, pensemos em Cocos, considerando que os locais e os sujeitos produzem poéticas singulares para a manifestação.

O Cariri, uma das Microrregiões do Ceará, está localizado na Mesorregião Sul do Estado e é composto por oito municípios: Barbalha, Crato, Jardim, Juazeiro do Norte, Missão Velha, Nova Olinda, Porteiras e Santana do Cariri. Possui uma área aproximadamente de 4.115,828 km² e uma população de 528.398 habitantes (IBGE, 2009) $)^{6}$.

Em trabalho de campo realizado em Juazeiro do Norte e Crato, a respectivamente 540 e 529 quilômetros da capital cearense, identificamos quatro grupos de Cocos. Esses grupos revelaram-se singulares por praticarem os cantos dançados diferente dos Cocos de praia comumente vistos, no Ceará, nas mídias e nos encontros culturais. Usam diferentes instrumentos, dançam com passos mais lentos, fazem menos improviso na música, além de maior presença feminina, pois nos Cocos de praia é predominante a presença masculina. (SILVA, 2008; FARIAS, 2012; ARAUJO, 2013).

As mulheres integrantes desses grupos são, em sua maioria, agricultoras ou profissionais autônomas. Nos grupos assumem as funções de coquista, tiradora, ou Mestra de Coco - aquelas que cantam - e de dançadeiras. Cada grupo possui uma trajetória particular, assim como formas específicas de dançar e de cantar.

O grupo mais antigo, fundado em 1979, chama-se "A gente do Coco". Este se organizou a partir da iniciativa de Edite Dias de Oliveira Silva ${ }^{7}$, que teve o primeiro contato com a dança ainda menina. Em 1979, Dona Edite, então monitora do Mobral, com outra monitora chamada Antônia Selma, já falecida, resolveu fazer uma festa de Coco e preparou uma apresentação na Praça da Sé da cidade do Crato. Com o fim do Mobral, a Associação das Mulheres da Batateira ${ }^{8}$ formou um grupo para organizar a dança das mulheres. Dona Edite assumiu um papel caracterizado por ela como: “o que eu faço é coordenar o grupo, ir atrás das meninas, da roupa, do cachê, eu chamo de a coordenadora do grupo.” (SILVA, 2013).

Atualmente o grupo é formado por 17 pessoas, sendo dois homens responsáveis por tocar os instrumentos, um bombo e um pandeiro. Pelo grupo já passaram três Mestras de Coco. A primeira foi Antônia Selma. Após seu falecimento, sua mãe, Filomena Gomes, a substituiu e, quando esta faleceu, a dançadeira Maria de Lourdes Moraes ${ }^{9}$ assumiu o papel de Mestra. Sobre como aprendeu a cantar e a dançar, a Mestra relembra: "Aí um dia Dona Edite chegou lá em casa perguntando se eu sabia cantar, eu disse: eu já cantei, a

2 Com relação à métrica existem os Cocos de embolada, em quadras, de dez pés, de rima, de roda e tombado. Com relação à música encontra-se os Cocos de ganzá e o de zambê. Com relação ao local praticado, temos os Cocos de praia, de usina, de sertão e pé de serra. Por fim, com relação à coreografia, identificam-se os Cocos de roda, de sapateado, de filas, de parelhas e o solto (CASCUDO, 2012; ANDRADE, 2002).

3 Os instrumentos normalmente são: caixão, zambê e ganzá.

4 A umbigada é o ato dos dançadores de encostarem seus umbigos, pode ser simulado, em sinal de desafio.

5 Iguape, Caetanos de Cima, Fortaleza, Trairi, Balbino, Aracati, Majorlândia, Canoa Quebrada, Quixaba, Pecém, Almofala e Cariri.

6 Esta microrregião, caracterizada por uma significativa dinâmica cultural, é palco de diversos grupos de cultura popular, como bandas cabaçais, grupos de reisado, maneiro pau, maracatu, coco, entre outros.

7 Dona Edite, 73 anos, nasceu em Pernambuco e em 1969 mudou-se para o Crato. É agricultora, costureira e foi professora do Mobral, participa de movimentos comunitários no bairro onde reside.

8 Batateira é o codinome do Bairro Gisélia Pinheiro no Crato.

9 Maria de Lourdes, 73 anos, é agricultora e costureira. 
gente não esquece não. E aí eu fiquei, gosto da brincadeira. Eu canto as músicas velhas que meu pai cantava, que eu tenho gravada, eu gravo aqui na cabeça.” (MORAES, 2013). O grupo dança o Coco de roda, já realizou apresentações em Fortaleza e em São Paulo.

Outro grupo é o "Amigas do Saber", fundado por Maria Nogueira ${ }^{10}$, que aprendeu a dançar e a cantar com seu avô e seu pai no Sítio Juá, município do Crato. A escola onde estudava realizava brincadeiras ao final de cada ano letivo e, quando Maria da Santa concluiu a $8^{a}$ série, fez um grupo de Coco com as mulheres da escola e do Sítio Juá, em 2003, como relembra a Mestra: "Me convidaram pra eu participar de uma escola do EJA pra concluir a $8^{a}$ série. Aí, então, foi dentro da sala de aula [...] aí eu fui e inventei de ensaiar a dança do coco [...] vamos dançar o coco, aí eu saí ensaiando passo por passo e deu certo." (NOGUEIRA, 2014). Atualmente o grupo possui 13 mulheres, que variam de 12 a 76 anos, e três homens, que tocam pandeiro, violão e bombo. O ganzá é tocado pela Mestra. As músicas do grupo são criadas por Maria da Santa e seu esposo. O grupo pratica o que chamam de Coco baião, pois o pandeiro proporciona uma batida semelhante à do baião.

O terceiro grupo, Coco Frei Damião, foi fundado por Marinêz Pereira do Nascimento ${ }^{11}$, que relata a sua iniciação na dança: "A história da dança do Coco já vem nas primeiras gerações da minha família, um rapaz de Alagoas, casou com a irmã do meu avô paterno, o nome dele é Antônio, mais conhecido como Tio Dunízio, morava no Crato.” (NASCIMENTO, 2013). Em 2003, a Mestra começou a dançar Coco no grupo do Mestre Dodô ${ }^{12}$, continuidade do grupo de Tio Dunízio, formado de homens e de mulheres da mesma família. Marinêz saiu desse grupo em 2005, após aceitar um convite para ensinar a dança, contrariando a vontade do Mestre. Então, resolveu formar um grupo de Coco com mulheres de sua família, que possuem de 8 a 76 anos. O grupo dança e canta os Cocos de roda e travessão, utilizam apenas o ganzá, balançado pela Mestra que faz as emboladas.

O quarto grupo tem como Mestra Ana ${ }^{13}$, que conheceu a dança quando criança, através de seus avós e pais, sobre essa época, recorda: "A vida era cansada, mas na hora de dançar eu tava alegre! Aí [era] nos terreiros, batia aqueles terreiro de terra grande, parece que tou vendo. Compadre Chico Carnaúba era o tirador de Coco, esses Coco que eu canto hoje, tudo era dele. Nós cantava a noite toda!” (NANINHA, 2013). Nessa época, a Mestra tinha 8 anos de idade; a prática acontecia no Sítio Baixio do Muquém, no Crato, onde residia com seus familiares. Após se mudar para o bairro Alto da Penha, parou de dançar e de brincar. A Mestra retomou o canto em 2011, com o incentivo de sujeitos locais envolvidos com as culturas populares, e juntou-se à Sociedade Cratense de Auxílio aos Necessitados (Scan), que atende a idosas, formando um grupo de Coco que ensaia semanalmente.

Além de esses grupos trazerem novos sujeitos, as mulheres, como criadoras da arte e da poesia dos Cocos, também revelam novas formas no saber/fazer da prática cultural, cada qual com suas peculiaridades, criam modalidades do cantar e do dançar. Ao se apropriarem da dança, as mulheres produzem singularidades e pluralidades, (re)inventando uma tradição.

\section{III - Algumas movimentações possíveis}

Partindo da perspectiva de que as produções históricas são desenvolvidas a partir de problemas tecidos na relação entre pesquisador, temporalidades e sujeitos (BLOCH, 2002), perguntamos: Como os grupos de Cocos de mulheres do/no Cariri cearense se apropriam da dança, (re)inventando uma tradição?

Entendemos que para compreender esse processo é preciso analisar a trajetória social da prática cultural no local, essa deve expressar a preocupação em investigar como se deu o surgimento dos grupos de Coco de mulheres na região do Cariri. Percebemos, através das entrevistas, um primeiro momento em que as atuais Mestras conviveram e se introduziram na brincadeira, no dançar e no cantar, através de Mestres homens, como Carnaúba, Dunízio, Antônio Silva, Joaquim Preto e Antônio Pereira, já falecidos. Sobre como a manifestação acontecia, elas nos contam:

10 “Dona” Maria, conhecida como Maria da Santa, 56 anos, é agricultora e coordena projetos religiosos.

11 Marinêz do Nascimento, 47 anos, nasceu em Juazeiro do Norte, é bordadeira e cozinheira.

12 Este grupo não será pesquisado, pois este estudo enfoca apenas os grupos de Cocos de mulheres.

13 "Dona” Ana, ou Naninha, 76 anos, nasceu no Crato, é agricultora e costureira. 


\section{Artigos}

Aí o meu pai era um fino cantador de Coco, Antônio Moraes da Silva, aí toda tapagem de casa que tinha o povo ia chamar ele, né? Era a noite todinha, não tinha tanta mulher assim, era mais homem, aí a pisada era bonita, viu! Nesse tempo tinha 14 anos [...] A diversão nesse tempo num era forró que nem hoje, era coco, cantoria, brincadeira de reisado, era. (MORAES, 2013).

Sempre era assim, quando construíam a casa de taipa, aí eles convidavam as pessoas vizinhas para aterrar a casa, todo mundo ia dançar o Coco amassando o barro. Também nos períodos de plantio do arroz. (NOGUEIRA, 2013).

Os instrumentos era um único só, que hoje o povo bota violão, bota isso, bota aquilo, naquele tempo não tinha. Era uma lata, dessas de leite Ninho, botava meia de milho, e ele cantando e balançava, era o que a gente chama de ganzá, aí dançava a noite todinha, quando era no outro dia amanhecia branco até a pestana de poeira. (NANINHA, 2013).

A prática era realizada com instrumentos improvisados com latas, caroço de milho, pedras, a fim de reproduzir um som semelhante ao do ganzá. Os Mestres eram todos homens que cantavam para mulheres e homens dançarem em farinhadas ou para pisar o chão das casas de taipa, fazendo da dança um momento de diversão/celebração seja da realização do trabalho, ou da nova casa, unindo o tempo do trabalho com o do lazer. Esse "outro tempo" também é representado nas músicas que cantam:

Meu nome é Marinêz, sou filha de Mariainha/ Sobrinha de tio Dunízio que canta coco e faz rima/ Eu vi o aboio do vaqueiro, eu vi o gado passar/ Menina abra a porteira e deixa o gado entrar/ Eu vi o aboio do vaqueiro, eu vi o gado passar/ Menina abra a porteira e deixa o gado entrar/ Ele veio de Alagoas, casou-se com minha tia/ E foi morar do Gonçalves formando a sua família/ Eu vi o aboio do vaqueiro, eu vi o gado passar. (NASCIMENTO, 2012)

De manhã tu moi o barro, de tarde tu vai tapar/ Com a turma dançando o coco pro terreiro aterrar/ Quando eu era pequenina, só comia rapadura/ Quando eu via a professora, ficava de cara dura [...] Plantei um pé de feijão/ Nasceu um pé de mamão/ Eu só vivo lá na roça pra ganhar o meu pão. (BATATEIRA, s/d)

Em suas canções também identificamos a referência a elementos que compõem esse passado narrado da vivência da dança. Percebemos que as letras mesclam suas vivências no campo - fazendo referência ao gado, ao vaqueiro, assim como à paisagem rural e às plantações - com as suas histórias de vida, nas quais se entrelaçam as histórias das suas famílias e a prática de dançar para aterrar o chão das casas.

Sobre a entrada delas na dança, relembram:

Era tudo no Baixio, aí eu fui morar no Lobo, mocinha com 12 anos, lá ainda tinha, no Lobo ainda tinha quando tinha as farinhada. Aí depois vim pra aqui pro Alto da Penha, aí se acabou, acabou-se esse negócio de Coco, ninguém falava daquilo. Eu cantava muito nesse tempo. Aí parou. João do Crato chegou aqui e perguntou se eu sabia, eu sei de tudo, tá tudo na cabeça, daquele tempo, foi agora, em 2011. (NANINHA, 2013).

Eu fui concluir a $8^{a}$ série, aí o grupo foi fundado na escola Pedro Felício, a ideia foi porque nos final de ano tinha comadre Toinha que nos finais de ano ela inventava umas brincadeiras, aí eu comecei estudando e pensei: eu vou fundar um grupo aqui! Isso em 19 de julho de 2003. (NOGUEIRA, 2013).

Nos Cocos do Crato, observamos que após o falecimento dos Mestres a dança deixou de ser praticada, sendo retomada em contextos diferentes por mulheres que outrora haviam sido dançadeiras e tornaram-se Mestras. Já em Juazeiro do Norte, Marinêz, após um desentendimento, rompeu com o grupo de Coco que fazia parte e criou um novo grupo. Este se diferencia, pois não está associado a um bairro, um sítio, ou uma instituição, mas a uma família, as integrantes fazem parte da mesma família.

Todas essas situações expressam diferentes formas de mudar papéis sociais atribuídos às mulheres na produção de uma prática cultural popular, ao assumirem o lugar de Mestras e fundarem grupos de mulheres, incidindo sobre suas identidades. Nesse processo de apropriação e de ressignificação da dança, as mulheres se constituem como "as mulheres dos Cocos", como são chamadas. Ao serem questionadas sobre o significado do dançar em suas vidas, afirmam:

Pra mim, o Coco é alegria, é diversão, é cultura, primeiro que tá no sangue, eu não quero saber se é de roda, trocado, eu só quero participar, eu gosto de tudo, reisado, banda cabaçal, mas o Coco bate mais forte, o Coco é tudo pra mim. [...] o Coco não é mais para fazer piso de casa, hoje é cultura, é história. (NASCIMENTO, 2013).

Vou cantar, vou cantar/ Pra cantar não tem idade/ Quanto mais a gente canta, nasce a felicidade/ Nasce a felicidade de dentro do coração/ A gente que canta o coco, sente uma grande emoção. (NOGUEIRA, s/d). 
Pra mim mudou muita coisa, porque eu vivia era prisioneira, só de casa, só da roça pro trabalho em casa, e sem sair pra nenhum canto, sem conhecer ninguém, sem conhecimento de ninguém, aí depois que eu entrei nesse coco abençoado, aí comecei a andar mais ela aí, graças a Deus, tem grande conhecimento de todo canto. Acho muito bom, de que eu tá em casa só pensando em coisa que não adianta, né? (NEIDE, 2014) ${ }^{14}$.

O dançar/cantar coco, na vida dessas mulheres, parece ocupar um lugar do lazer/diversão, proporcionando a integração e o convívio com outros sujeitos, além de ser uma prática que remete a suas histórias de vida e de suas famílias. Há indícios de que a apropriação dessa prática e a sua experimentação modificou a condição dessas mulheres, pois como sugere a dançadeira Maria Neide, antes era "da roça pro trabalho em casa", assim, afirmam que o coco trouxe conhecimento, levou-as a lugares desconhecidos, como os espaços públicos (PERROT, 1989). Esse mesmo significado é reafirmado pela dançadeira Maria das Dores $(2014)^{15}$ : "Mudou a diversão quando a gente sai, vai se divertir, conhece lugares, é uma diversão pra gente, a gente gosta né? Porque antes a gente vivia só em casa, né? Ia pra missa e ficava em casa, aí depois dessa brincadeira, a gente tem essa diversão, conhece mais lugares".

Assim, ao perguntarmos como se dá a apropriação da dança pelas mulheres, entendemos que esta se dá com a (re)invenção dessa dança como uma tradição. Esse discurso da dança como tradição pode ser problematizado através das falas das Mestras e dançadeiras, percebendo que existem tensões e disputadas nesse processo. Em suas falas, temos que:

Existe vários grupos que a gente vê como é que ele dança e é totalmente diferente do que a gente dança, não tem esse negócio de fazer aqueles passos de antigamente. A gente vê assim muito parecido com quadrilha, dança de quadrilha junina, tem até uns grupos que a gente diz 'não, eu não tou achando', mas como diz que é uma dança de coco, aí a gente cada um em seu lugar, e cada um faz do jeito que pode apresentar (NOGUEIRA, 2014).

Nós não tem o pandeiro, como Maria da Santa, Maria da Santa tem o pandeiro e um bombo, né, e tem um violão, né. Porque nós comecemos do mesmo jeito que foi do tempo véi, nós tamo no tempo véi, desse mesmo jeito. Não dá certo, comparação, se bater um pandeiro atrapalha, atrapalha nossa pisada. (SILVA, 2014) ${ }^{16}$.

A tradição, assim como a originalidade, é reivindicada e associada ao "fazer como antigamente", seja no uso dos instrumentos, seja no cantar, seja no dançar. Por exemplo, como sugere Naninha, "Aí, eu comecei a cantar, se agradaram, aí ficou. É o Coco original, é o Coco original, porque esse não é inventado, vamos botar esse Coco original pra frente!” (2013). Na fala da Mestra, o seu fazer é associado a uma originalidade por não ser inventado, tendo em vista que canta músicas aprendidas com antigos Mestres da região.

Entretanto, compreendemos que as tradições se constituem por um conjunto de práticas e de símbolos, compostas por regras e aceitas socialmente, tendo naturezas ritualísticas ou simbólicas que inculcam certos valores e normas de comportamento, através da repetição, gerando uma continuidade com relação ao passado. Mas:

$\mathrm{Na}$ voz e no corpo atualiza-se a tradição cosida com as fibras do lembrar e do esquecer, do ontem e do agora, da mobilidade, das circularidades da cultura. O fio da tradição conduz o homem pelos labirintos das infinitas possibilidades do fazer cultural e justo nas diferenças dessas encruzilhadas nos reconhecemos. (AMORIM, 2007: 50).

Portanto, as tradições são dinâmicas, transformadas e (re)construídas nas tramas sociais, inserem os homens em fazeres culturais que possibilitam o encontro e a construção de identidades. A (re)invenção de uma tradição se dá a partir de transformações que modificam padrões sociais que expressavam "velhas tradições”, produzindo outros padrões. Assim, as tradições podem ser construídas, institucionalizadas e de difícil localização no tempo (HOBSBAWM; RANGER, 1997). Nessa perspectiva, pensamos a apropriação da dança pelas mulheres como uma (re)invenção de uma tradição, pois promoveu uma ruptura em uma dança popular que no Cariri tinha como Mestres homens, e que no Ceará, destaca-se como dança de pescador.

14 "Dona" Maria Neide, 65 anos, é agricultora e dança coco no grupo A gente do Coco da Batateira.

15 A dançadeira Maria das Dores, 70 anos, é agricultora e dança no grupo Frei Damião.

16 Maria Alta da Silva, vulgo Marieta, 75 anos, é agricultora e a mais velha dançadeira de Coco do Grupo Frei Damião, aprendeu a dançar Coco com Tio Dunízio e permanece na brincadeira. 
Artigos

Assim, essa tradição se estabelece pela produção de singularidades e de pluralidades, transformando-a e instituindo-a formalmente, criando um Coco de diferença que não se repete como o mesmo, atualiza-se articulando passado e presente (DELEUZE, 2006). Pois, mesmo mantendo determinados elementos do passado, as mulheres introduzem outros - como o violão, o pandeiro, outros passos, outro ritmo, novas músicas, figurino -, além de produzirem outra poética que é significada de diferente forma, pois que a dança não é praticada atualmente para tapar piso de casas, ou celebrar uma farinhada.

Estas multiplicidades dos Cocos apresentam singularidades e pluralidades, continuidades e descontinuidades, nas suas formas de manifestações, que "reatualizam" uma tradição, a partir da teatralização e da ressignificação. Assim, a dança se reinventa em compassos e arquiteturas de sons e de passos, nos quais os Cocos se atualizam mudando e se diversificando, tornando-se elemento do passado/presente, entre o dançar e as memórias dançantes de mulheres.

\section{Referências bibliográficas:}

AMORIM, Maria Alice. 2007. No visgo do improviso ou a peleja virtual entre cibercultura e tradição. Comunicação e mídia digital nas poéticas de oralidade. São Paulo, SP. Dissertação de mestrado. Pontíficia Universidade Católica de São Paulo, 118p.

ANDRADE, Mário de. 2002. Os cocos. Belo Horizonte, Itatiaia, 512p.

ARAUJO, Ridalvo Felix de. 2013. Na batida do corpo, na pisada do cantá: inscrições poéticas no coco cearense e candombe mineiro. Belo Horizonte, MG. Dissertação de mestrado. Universidade Federal de Minas Gerais, 149p.

ARRAIS, Joubert de Albuquerque. 2013. Quando fazer é pensar e pesquisar: andanças epistemológicas. Dança, v.2, n.1: 58-72.

AYALA, Maria I.; AYALA, Marcos (orgs.). 2000. Cocos: alegria e devoção. Natal, EDUFRN, 304p.

BARROSO, Oswald. 1982. O coco de praia em Majorlândia. In: CARIRY, Rosemberg; BARROSO, Oswald (orgs.). Cultura insubmissa: estudos e reportagens. Fortaleza, Secretaria de Cultura e Desporto.

BATATEIRA, A gente do Coco da. Forró Balancear. In: Barra do Dia. Pindoretama Record's, s/d. 1 CD. Faixa 4. BLOCH, Marc. 2002. Apologia da História on O Ofício de Historiador. Rio de Janeiro, Jorge Zahar, 160p.

BOSI, Ecléa. 1994. Memória e Sociedade: lembranças de velhos. 3. ed. São Paulo, Companhia das letras, 484p.

CAROZZI, María J. (coord.). 2011. Las palabras y lós passos: etnografias de la danza em la ciudad. Buenos Aires, Gorla, 263p.

CASCUDO, Câmara. 2012. Folclore do Brasil. 3. ed. Natal, FJA, 230p.

DELEUZE, Gilles. 2006. Diferença e repetição. 2. ed. Rio de Janeiro, Graal, 437p.

DORES, Maria das. Maria das Dores: entrevista [abr. 2014]. Entrevistadora: Camila Mota Farias. Juazeiro do Norte, CE: 2014. Arquivos de mp3.

FARIAS, Camila Mota. 2012. O coco vem de dentro da gente: ressignificações culturais da dança do coco em Balbino CE (1997-2012) . Fortaleza, CE. Monografia de graduação. Universidade Estadual do Ceará, 108 p.

FENTRESS, James; WICKHAM, Chris. 1992. Recordar. In: FENTRESS, James; WICKHAM, Chris. Memória social: novas perspectivas sobre o passado. Lisboa, Teorema, p. 13-58.

GEERTZ, C. 1989. A Interpretação das Culturas. Rio de Janeiro, Guanabara Koogan, 323p.

GREINER, Christine. 2012. O registro da dança como o pensamento que dança. Revista D'Art, v. 4: 38-43.

GUARATO, Rafael. 2010. História e dança: um olhar sobre a cultura popular urbana - Uberlândia 1990/2009.

Uberlândia, MG. Dissertação de mestrado. Universidade Federal de Uberlândia, 226p.

HOBSBAWN, Eric; RANGER, Terence (orgs.). 1997. A invenção das Tradições. Rio de Janeiro, Paz e Terra, 316p. 
INSTITUTO BRASILEIRO DE GEOGRAFIA E ESTATÍSTICA - IBGE. Censo Agropecuário. Rio de Janeiro, 2006. Disponível em: <www.ibge.gov.br>. Acesso em: 14 de maio de 2014.

JUCÁ, Gisafran Nazareno Mota. 2003. A oralidade dos velhos na polifonia urbana. Fortaleza, Premius, 129p.

MONTEIRO, Marianna. 2011. Dança Popular. Espetáculo e Devoção. São Paulo, Editora Terceiro Nome, 239p.

MORAES, Maria de Lourdes. Maria de Lourdes Moraes: entrevista [ago. 2013]. Entrevistadora: Camila Mota Farias. Crato, CE: 2013. Arquivos de mp3.

NANINHA, Ana: Ana Naninha: entrevista [4 ago. 2013]. Entrevistadora: Camila Mota Farias. Crato, CE: 2013. Arquivos de mp3.

NAPOLITANO. Marcos. 2005. História \& Música. 3. ed. Belo Horizonte, Autêntica, 117p.

NASCIMENTO, Marinêz Pereira do. Aboio do vaqueiro. In: Coco. Projeto Mestres Navegantes, 2012. 1 CD. Faixa 9.

NASCIMENTO, Marinêz Pereira. Marinêz Pereira do Nascimento: entrevista [ago. 2013] Entrevistadora: Camila Mota Farias. Juazeiro do Norte, CE: 2013. Arquivos de mp3.

NEIDE, Maria. Maria Neide: entrevista [abr. 2014]. Entrevistadora: Camila Mota Farias. Crato, CE: 2014. Arquivos de mp3.

NOGUEIRA, Maria. Maria Nogueira: entrevista [abr. 2014]. Entrevistadora: Camila Mota Farias. Crato, CE: 2014. Arquivos de mp3.

NOGUEIRA, Maria. Maria Nogueira: entrevista [ago. 2013]. Entrevistadora: Camila Mota Farias. Crato, CE: 2014. Arquivos de mp3.

NOGUEIRA, Maria. Pra cantar não tem idade. In: Flor do Liro. Pindoretama Record's, s/d. 1 CD. Faixa 8.

PERROT, Michelle. 1989. Práticas da memória feminina. Revista Brasileira de História, v.9, n. 18: 9-18.

PESAVENTO, Sandra Jatahy. 2003. História \& história cultural. Belo Horizonte, Autêntica, 130p.

PORTELLI, Alessandro. 1997. Tentando aprender um pouquinho. Algumas reflexões sobre a ética na história oral. Projeto História: Revista do programa de estudos pós-graduados em História e do Departamento de História da PUC-SP, n.15:13-49.

PORTELLI, Alessandro. 2013. A Morte de Luigi Trastulli e outros ensaios. Ética, memória e a acontecimento na História Oral. Lisboa, Unipop, 205p.

ROCHA, Thereza. 2012. Dança | Filosofia: verso e reverso de um dizer. Urdimento, n.19: 73-82.

SANTHIAGO, Ricardo. 2013. História oral e as artes: percursos, possibilidades e desafios. História Oral, v. 16, n. 1: $155-187$.

SILVA, Djanilson Amorin. 2008. Os cocos no Ceará: dança, música e poesia oral em Balbino e Iguape. Fortaleza, CE. Dissertação de mestrado. Universidade Federal de Fortaleza, 93p.

SILVA, Edite Dias de Oliveira. Edite Dias de Oliveira Silva: entrevista [ago. 2013]. Entrevistadora: Camila Mota Farias. Crato, CE: 2013. Arquivos de mp3.

SILVA, Maria Alta da. Maria Alta da Silva: entrevista [abr. 2014]. Entrevistadora: Camila Mota Farias. Juazeiro do Norte, CE: 2014. Arquivos de mp3.

VILELA, Lilian Freitas. 2010. Uma vida em dança: movimentos e percursos de Denise Stutz. 150p. Campinas, SP. Tese de doutorado. Universidade Estadual de Campinas, 150p. 